\title{
An Analysis of Enhanced Faculty Engagement on Student Success and Satisfaction in an Online Classroom
}

\author{
-Mingzhen Bao: College of Liberal Arts, Ashford University, San Diego, CA, USA. \\ Adam L. Selhorst: College of Liberal Arts, Ashford University, San Diego, CA, USA. \\ Teresa Taylor Moore: College of Liberal Arts, Ashford University, San Diego, CA, USA. \\ Andrea Dilworth: College of Liberal Arts, Ashford University, San Diego, CA, USA.
}

ABSTRACT: Difficulty building meaningful student and instructor relationships can create a challenge for online instructors. A Faculty of Practice (FoP) role was created in a large online university requiring greater faculty engagement to bolster student achievement. This study examined the impact of the FoP role on student success and satisfaction over a 6-month period. The position emphasized an increased engagement through enhanced personalized learning, subject-matter expertise, discipline mentoring, and community building. The increased engagement was promoted through requirements mandating a consistent presence in the classroom, personalized email interactions with students prior to course start, promotion and instruction of material through individual conferences, outreach to students with late or missing assignments, and weekly office hours including video conference options. None of these requirements are mandated for Associate Faculty $(A F)$ teaching the courses. Data on student success included an analysis of student GPA, pass rates, completion rates, and progression to next course rates for FoP and AF courses. Student satisfaction was evaluated through the analysis of Student End-of-course Surveys (EoCS). Student data showed a significant increase in student GPA with the FoP when compared to AF courses. No differences were seen in pass, completion, or progression rates. Increase in student satisfaction for FoP courses as measured by EoCS was seen upon comparison with AF. Students noted a greater connection with the FoP and indicated stronger relationships with the FoP. Based on the analysis, we conclude the FoP role has the potential to improve student success and satisfaction in the online classroom.

Key words: Online education, Student success, Student satisfaction, Engagement, Faculty.

\section{Introduction}

Online education is welcomed by a growing number of institutions as a means of providing accessible education to students and allowing institutions to increase capacity beyond constraints of time or space (Gannon-Cook, 2010; Mueller, Mandernach, \& Sanderson, 2013). Through an asynchronous online learning environment, many working adults are able to approach their field of study and obtain degrees while maintaining full-time jobs and managing family life. The expansion of online education has amplified the demand for courses that are taught entirely online. In fall 2014, there were 5.8 million students enrolled in online courses, which covered $28 \%$ of students enrolled in degree-granting postsecondary institutions. Online enrollment was higher in private for-profit institutions with $61.4 \%$ of the 1.6 million students taking courses online (National Center for Education Statistics, 2016). While online education offers convenience 
and flexibility, challenges exist that must be addressed by faculty and educational institutions to enhance the learning experience.

A commonly discussed concern surrounding online education is the absence of student to faculty faceto-face interaction. Research has shown this lack of engagement can affect the students' connectedness to the instructor, their peers, and to the course material (Kemp \& Grieve, 2014). Further research from Kent State University illustrated student concerns over a lack of interpersonal interactions with professors in online courses (College of Communication and Information, 2017). Contrary to these findings, research exists suggesting that a lack of face-to-face interaction has no real impact on students' level of satisfaction in online courses (Arasaratnam-Smith \& Northcote, 2017; Rovai, Wighting, \& Liu, 2005). With data supporting and refuting concerns regarding the effects of online learning on student engagement and satisfaction, this study will address impacts of various levels of engagement on students in a large online university. To address the lack of interpersonal contact that comes along with distance education, many institutions are altering the faculty classroom role. One practice has been to create full-time faculty positions focused on classroom teaching and student mentoring while forgoing the traditional research duties. As early as 2004, institutions of higher education such as Duke University began altering faculty roles to enhance the student experience and level of achievement (Fogg, 2004). In 2016, the Teachers Insurance and Annuity Association of America (TIAA) conducted a study consisting of various higher education stakeholders on new faculty models and their perceptions (Kezar, Holcombe, \& Maxey, 2016). They discovered widespread consensus on the need to reconsider full-time faculty roles to better serve students, individual programs, and the institutions.

While data exist analyzing the role of student engagement on success and satisfaction, much of this research focuses on traditional students, or adult students learning in a traditional modality. The following study will focus on the efficacy of a FoP role created to enhance student and faculty engagement for adult learners in an entirely online modality.

\subsection{The Instructor as a Communicator}

In an environment consisting largely of text-based instructions and written assignments, adult learners tend to be concerned with the immediacy and efficacy of instructor communications. This communication may take the form of either personalized responses to students or the creation of engaging instructional materials. Arbaugh (2001) found that immediacy behaviors had a direct impact on student learning and course satisfaction. In this sense, immediacy described communication behaviors that reduce the social and psychological distance between people (Mehrabian, 1971; Myers, Zhong, \& Guan, 1998). Additionally, he noted that with advancements in audio and video technology, future studies might show enhanced correlations between immediacy and student achievement. These thoughts provide further justification for research focused on the effects of increased engagement on learners.

More recently, Schutt, Allen, and Laumakis (2009) examined student perceptions of instructors' immediacy behaviors in the online environment. While the research did not focus solely on adult learners, it did lend knowledge about the perceptions and expectations of immediacy for distance instructors. Schutt et al. found that people gained more from interactions with other individuals than they did with inanimate objects. Additionally, through the creation of learning videos that they characterized as either high immediacy or low immediacy, they determined that student perceptions of instructor effectiveness directly correlated to videos with behaviors that served to reduce the psychological distance between students and faculty. Baker (2010) supported these findings by reporting a positive correlation between immediacy and the learning, cognition, and motivation of students. This suggests that the quality of interactions has a significant influence on the student experience and various forms of faculty engagement should be tested to determine high impact instructional practices.

Similarly, Dixson, Greenwell, Rogers-Stacy, Weister, and Lauer (2017) argued that a mixture of media types improved immediacy in the online classroom. Additionally, they found that multiple types of nonverbal immediacy behaviors had an impact on the learning environment including a focus on instructor tone and direct feedback. Emoticons and figurative language enhanced student learning, while quality feedback on assignments improved student achievement. The use of video and audio feedback yielded an even greater sense of social presence and provided more evidence for an enhanced study into the use of

Vol. 1, No. 2, pp. 102-109 Funding: This study received no specific financial support.

Article History:

Received: 18 April 2018

Revised: 20 September 2018

Accepted: 13 November 2018

() 2018 by the authors; licensee Academic

Publishing Group

| 103 various tools to engage students in the online classroom. 


\subsection{The Instructor as a Mentor}

The expectations of adult learners extend beyond the communication competencies of instructors in an online course. Adult learners also seek out instructors who provide the capacity to mentor. Olwell (2017) notes that mentoring is a role that has been consistently at the bottom of the agenda for full-time faculty. The reason for this is likely due to traditional faculty roles and the relatively unchanging nature of the global faculty model. Olwell also suggests that faculty are often unwilling to discuss non-course-related content with students, which deepens the divide between students and instructors.

In Mentoring Adult Learners: A Guide for Educators and Trainers, Cohen (1995) provides his take on the essential aspects of an effective adult educator. Specifically, he includes six behavioral functions that he refers to as the "complete mentor role" consisting of:

a. Relationship emphasis to establish trust

b. Information emphasis to offer tailored advice

c. Facilitative focus to introduce alternatives

d. Confrontive focus to challenge

e. Mentor model to motivate

f. Mentee vision to encourage initiative

Rarely do we conceptualize the mentor role as one with so many aspects. While it is possible that instructors touch on many of these behaviors, a greater focus on a faculty role that includes a welldeveloped mentoring plan may prove vital to enhance student success and satisfaction. This point is further developed by Harden and Crosby (2000) who identified twelve characteristics of an effective instructor, including mentor, on-the-job role model, and teaching role model. For an adult learner, mentoring is a critical aspect in the online environment. These students are often working adults seeking advanced education to advance within their current role or looking to change careers. Given that, adult learners are more inclined to seek out the mentoring of faculty members.

\subsection{The Instructor as a Practical Teacher}

Unlike more traditional institutions, due to greater flexibility, a higher percentage of online instructors work in the field and teach as adjunct instructors. This is especially true in skills-based programs that evolve rapidly with changes in technology. Disciplines requiring changing skill sets would benefit most from having full-time faculty with ample experience in the field of study. However, regardless of the field, students can benefit from instructors with practical job experience. Harden and Crosby (2000) describe one faculty role as "information provider," divided between serving as a "lecturer" and a "clinical or practical teacher." They noted that, the General Medical Council in the UK stated in 1999 that the example of the teacher is the most powerful influence upon the standards of conduct and practice of every trainee. It can be argued that this model can be tailored to skills-specific disciplines such as journalism.

Brower and Steward (2015) further advocated for practical faculty. They observed many business schools responding by hiring professors of practice, or industry executives without PhDs. In an article focused on business faculty, Clinebell and Clinebell (2008) stated, to increase relevance, or the perception of relevancy, in their programs and to fill faculty vacancies in the face of shortages of doctorally-qualified faculty, many schools of business are turning to business practitioners, or executive professors, to teach business classes. The preeminent accrediting body for business schools, AACSB, now uses the term clinical faculty for business practitioners. We see the prevalence of such positions in fields such as medicine, law, and business. After discussing the needs of many adult online learners, it may prove useful to develop faculty roles based on practical teaching experience.

\section{Method}

\subsection{Course Model and Students' Expectations of Instructors}

All undergraduate courses at Ashford University are worth three credits and are five weeks in length, with the exception of laboratory courses, none of which were utilized for this study. Courses utilize a standardized design, and are composed of a combination of weekly readings, assignments, quizzes, and mandatory participation in discussion boards. Instructors (full-time and part-time) are scheduled to teach based on areas of expertise and availabilities. Requirements dictate they post weekly guidance prior to the beginning of each week and answer student emails and questions within 48 hours. Discussion board grades 
are posted within 72 hours after the end of each week, and assignment grades and feedback are due within six days after the submission due date. Individualized instructor choices are via inclusion of supplemental course content, interaction with students, and nature of feedback.

\subsection{Faculty of Practice and Teaching Duties}

The Faculty of Practice (FoP) position is a full-time faculty role that supports the university primarily through teaching. This role carries a full teaching load of 25-30 courses per year and participates in high engagement teaching practices aimed at student success and retention. The faculty is responsible for instructor expectations described in the previous section. In addition, subject-matter expertise, discipline mentoring, and community building become a primary focus of the role to enhance student and faculty classroom engagement (see Table 1).

Table-1. Expectations of Faculty of Practice.

Create a Video Introduction in weekly guidance and utilize multimedia resources to enhance student
learning
Respond to student emails and questions within the next day.
Respond to all students at least once each week in discussion boards.
Provide detailed guidance and feedback for all assignments
Reach out to students via email if assignments have not been submitted, and allow leniency when
criteria are met.
Contact each student by email at least once per week during the course or the week prior to the
beginning of the course.
Hold weekly office hours to facilitate student learning.

\subsection{Instructor Participants}

The Journalism and Mass Communication (JMC) program hired one FoP in April 2017. The instructor previously worked as a part-time JMC Associate Faculty (AF) member, commonly referred to as an adjunct instructor. Following conversion from the AF to the FoP role, the instructor began teaching under the new expectations detailed above. Comparisons between FoP students and AF students were then compared over the following $62 \mathrm{JMC}$ courses launched between May and November 2017. Besides one course excluded due to missing evaluations, 20 courses taught by the FoP and 41 taught by JMC AF were analyzed for statistical differences in student success and satisfaction.

\subsection{Operationalization of Student Achievement and Satisfaction}

Differences in student success were measured by comparing grade point average (GPA), course completion rates, pass rates, and next-course progression rates. Pass rates included the percentage of students who received a D- (60\% of course grades) and above. Next-course progression rates evaluated the percentage of students continuing to the next course within the following two weeks. Student satisfaction was collected through end-of-course surveys (EoCS) provided to all students in the final week of the course (see Appendix). For students taught by the FoP, their reflections were recorded through an additional Qualtrics online survey measuring their satisfaction with the role.

\section{Results}

Student achievement and satisfaction data were checked for normality and linearity using Skewness and Kurtosis statistics in SPSS version 24. Multivariate General Linear Model (MANOVA) analysis was conducted to examine the difference in student achievement and satisfaction between courses taught by the FoP and the control group. Tests for homogeneity assumptions and evaluations of effect sizes and power for significant results were also included. Results showed a main factor of faculty status on student achievement and satisfaction $(\mathrm{p}=.003, \eta \mathrm{p} 2=.269)$ with a power of .932 . Descriptively, increases were noticed in average GPA, pass rates, next-course progression rates, and end-of-course survey scores in courses taught by the Faculty of Practice (Table 2, Figure 1). Post hoc Tukey's HSD tests indicated that the differences between the FoP and the control group were significant in GPA $(p=.001)$ and end-of-course surveys $(p=$ $.043)$. 


\begin{tabular}{|c|c|c|c|c|c|}
\hline Faculty Role & $\begin{array}{l}\text { Average GPA } \\
\text { (out of 4) }\end{array}$ & $\begin{array}{l}\text { Course } \\
\text { Completion } \\
\text { Rate }\end{array}$ & Pass Rate & $\begin{array}{l}\text { Next-course } \\
\text { Progression } \\
\text { Rate }\end{array}$ & $\begin{array}{l}\text { End-of-course Survey } \\
\text { Score (out of 4) }\end{array}$ \\
\hline $\begin{array}{l}\text { Faculty of } \\
\text { Practice }\end{array}$ & $3.30^{\mathrm{a}}$ & 95.24 & 90.79 & 83.20 & $3.73^{\mathrm{b}}$ \\
\hline Control Group & 2.75 & 95.96 & 86.37 & 78.22 & 3.39 \\
\hline
\end{tabular}
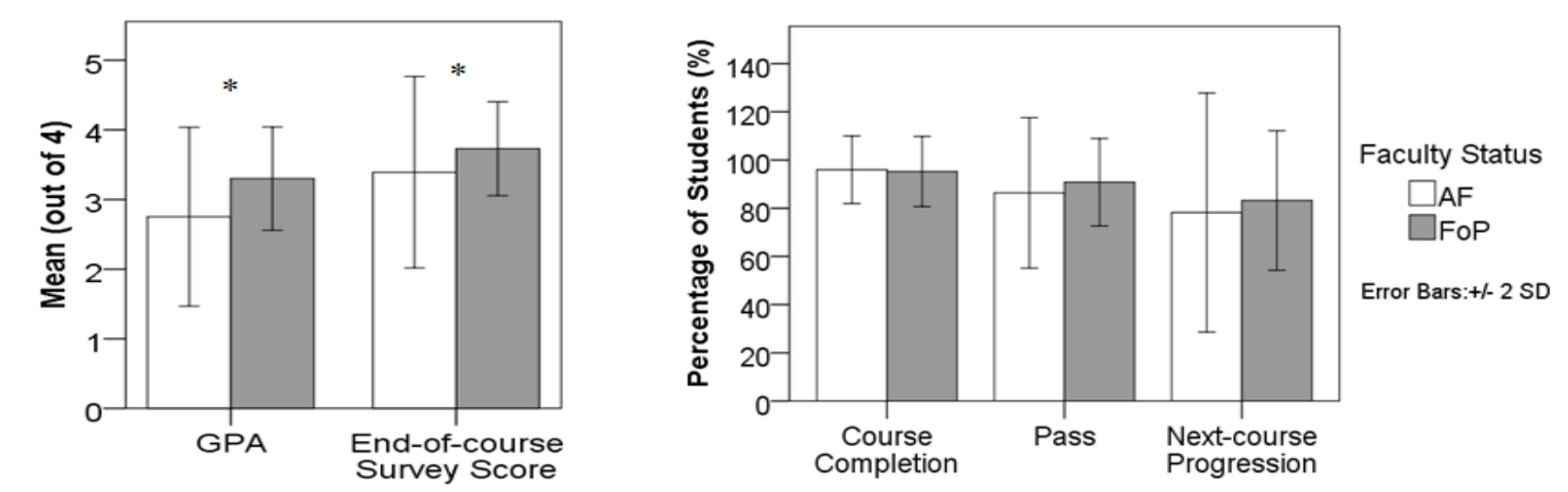

Note: * indicates significant results

32 students taught by the Faculty of Practice voluntarily participated in the Qualtrics survey. More than $90 \%$ of them agreed that the FoP served multiple positive roles in the classroom and beyond (Figure 2). The FoP was a coach and helping students solve course-related problems; a connector to the professional network and helping students with their career choices; a cheerleader and recognizing student achievement; and a challenger and giving students constructive feedback when they can do better.

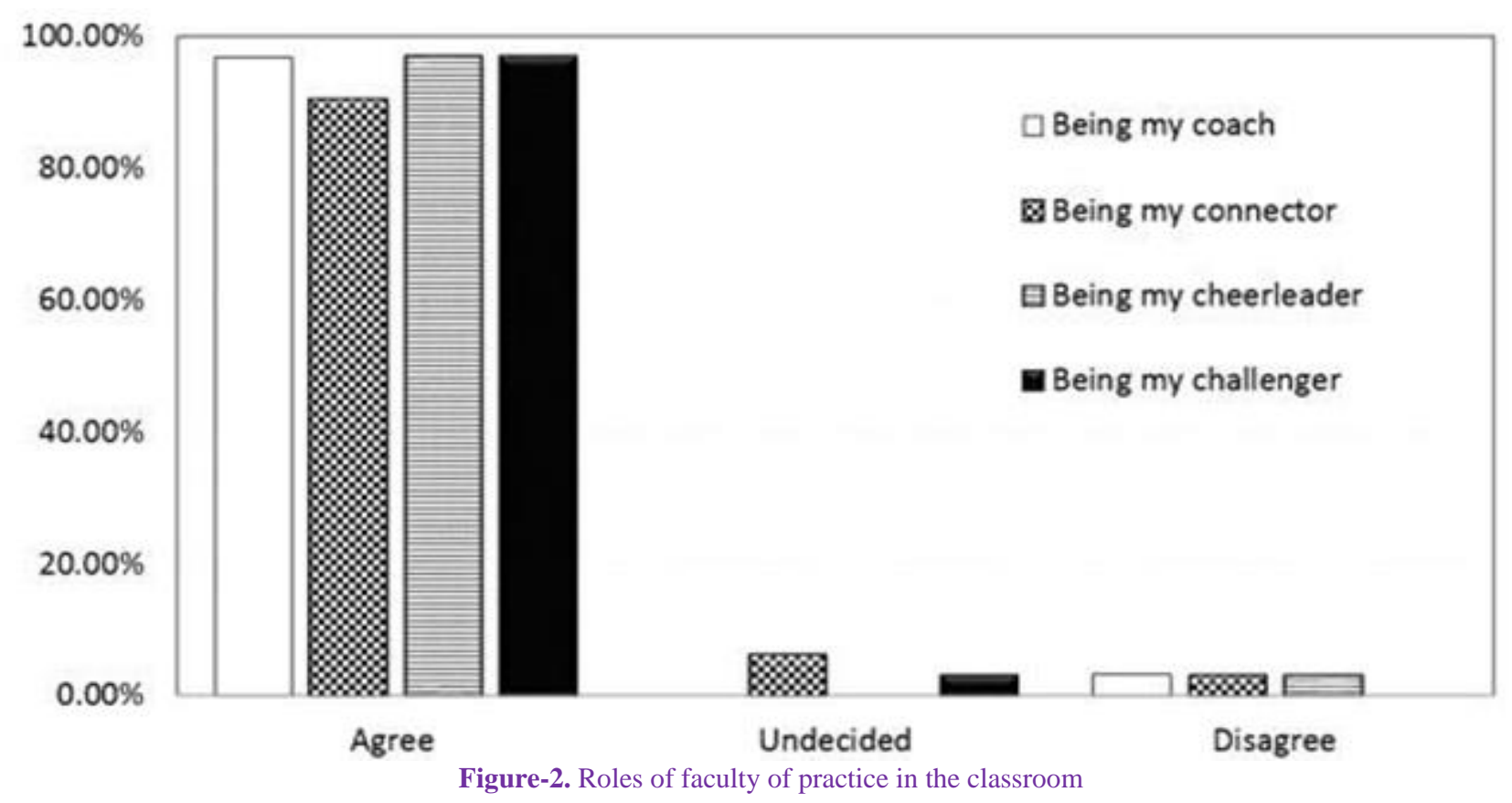

Student feedback illustrated a positive association with the Faculty of Practice expectations (Figure 3).

Students responded positively to receiving emails prior to the beginning of each course. Additionally, a

International Journal of Educ

2018

a

Corresponding Author: Mingzhen Bao

Funding: This study received no specific

Article History:

Received: 18 April 2018

Revised: 20 September 2018

Published: 21 December 2018

(C) 2018 by the authors: licensee Academic

Publishing Group 
majority of students appreciated the opportunities to connect with the faculty through video interaction and web-based office hours. Compared to other courses, students felt more connected to the instructor, and felt they received assistance in a more timely manner. 97\% of the students agreed that having the same FoP over multiple courses would allow for the development of trust and might produce a more effective long term relationship.

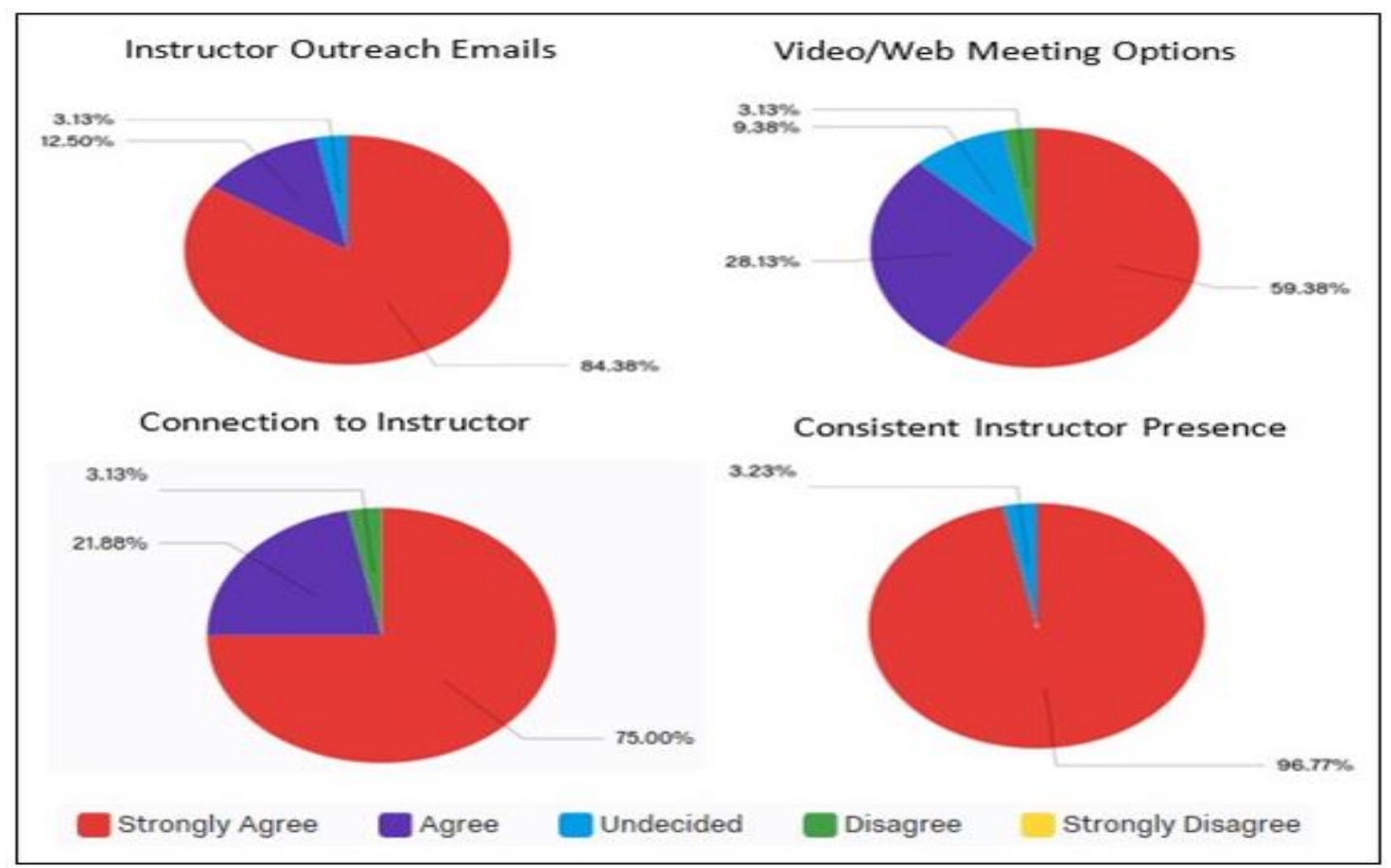

Figure-3. Student feedback on faculty of practice expectations

\section{Discussion and Conclusions}

Results indicated that students in this study were highly satisfied with the FoP instructor. Survey results illustrated a higher level of bonding with the FoP and an overall approval that significantly improved the students' experience when compared to courses taught by AF. This finding was further supported by EoCS results as scores were significantly higher for the FoP than for all AF. Coupled with increased satisfaction, students experienced higher levels of engagement and interest in the course material which research has shown is positively correlated with student grades (Carmichael, Callingham, \& Watt, 2017; Kahu, Nelson, \& Picton, 2017; Trowler \& Trowler, 2010). Consistently, student GPAs were significantly higher in FoP courses which indicates this improved academic achievement is positively impacted by the enhanced instructor engagement practiced throughout the course. A trend was seen for increases in pass rate and next-course progression rate among students in the FoP sections. Yet, the differences between FoP and AF were not statistically significant. As such, it is not possible to ascertain if the enhanced instructional actions undertaken by the FoP saved students who would have failed the sections or withdrawn from the university.

While the enhanced expectations performed by the FoP provided additional learning opportunities and directly led to increases in GPAs and student satisfaction, researchers recognize the inherent limitations of the study. It is obvious that comparing one FoP with a larger pool of AF is not ideal and that differences in GPA between the FoP and AF could be attributed to additional variables such as less stringent grading practices by the FoP. To mitigate such concerns, based on the positive correlation between student success and the FoP role illustrated in this paper, plans to hire more FoP positions and validate results through a larger study are underway.

Results illustrated higher GPA and EoCS scores for students taught by the FoP utilizing the enhanced expectations. However, the study does not allow researchers to determine if results are due to individual expectation changes, the group of expectation changes, or some combination of actions by the FoP. It is possible that a single FoP expectation change, such as 24-hour response time, is responsible for the gains in GPA and EoCS scores, while others are of no interest to the students. As such, researchers seek to determine 
the role of individual expectation changes on student success and satisfaction by testing the expectation components separately. This would allow us to understand the magnitude of each individual component in this study. Should specific actions prove to enhance the student experience, these initiatives could be adopted by all faculty within the university.

Finally, a stronger understanding of which actions are contributing to greater student success will allow us to further improve on these practices. For instance, if 24-hour response time leads to more successful students, it may be useful to study alternative models that reduce faculty response time even further. The use of SMS or text apps may provide an opportunity for a FoP to respond in as little as seconds. If reducing a 48 hour response time to 24 hours produces more successful students, there is a strong probability that reducing the 24-hour response time to just seconds will further these effects. Additionally, if video interaction proves to be a major component of enhanced student success and satisfaction, the incorporation of short video lectures, even if optional, may further bolster student success. Based on the findings of this research, a student-centered FoP position may elevate success and satisfaction in the online classroom, however, future research utilizing a larger FoP pool is needed to confirm results.

\section{References}

Arasaratnam-Smith, L. A., \& Northcote, M. (2017). Community in online higher education: Challenges and opportunities. Electronic Journal of e-Learning, 15(2), 188-198.

Arbaugh, J. B. (2001). How instructor immediacy behaviors affect student satisfaction and learning in web-based courses. Business Communication Quarterly, 64(4), 42-54. Available at: https://doi.org/10.1177/108056990106400405.

Baker, C. (2010). The impact of instructor immediacy and presence for online student affective learning, cognition, and motivation. The Journal of Educators Online, 7(1), 1-30. Available at: https://doi.org/10.9743/JEO.2010.1.2.

Brower, H., \& Steward, M. (2015). Business professors need to spend time in companies. Harvard Business Review.

Carmichael, C., Callingham, R., \& Watt, H. M. G. (2017). Classroom motivational environment influences on emotional and cognitive dimensions of student interest in mathematics. ZDM Mathematics Education, 49(3), 449-460. Available at: https://doi.org/10.1007/s11858-016-0831-7.

Clinebell, S. K., \& Clinebell, J. M. (2008). The tension in business education between academic rigor and real-world relevance: The role of executive professors. Academy of Management Learning \& Education, 7(1), 99-107. Available at: https://doi.org/10.5465/amle.2008.31413867.

Cohen, N. (1995). Mentoring adult learners: A guide for educators and trainers. Professional Practices in Adult Education and Human Resource Development Series. Florida: Krieger Publishing.

College of Communication and Information. (2017). Profs seek student input to improve online courses. Kent State University. Retrieved from: https://www.kent.edu/cci/news/profs-seek-student-input-improve-online-courses.

Dixson, M. D., Greenwell, M. R., Rogers-Stacy, C., Weister, T., \& Lauer, S. (2017). Nonverbal immediacy behaviors and online student engagement: Bringing past instructional research into the present virtual classroom. Communication Education, 66(1), 37-53. Available at: https://doi.org/10.1080/03634523.2016.1209222.

Fogg, P. (2004). For these professors, 'practice'is perfect. Chronicle of Higher Education, 50(32), A12-A14.

Gannon-Cook, R. (2010). What motivates faculty to teach in distance education? Lanham, MD: University Press of America, Inc.

Harden, R. M., \& Crosby, J. (2000). The good teacher is more than a lecturer: The twelve roles of the teacher. Medical Teacher, 22(4), 334-347. Available at: https://doi.org/10.1080/014215900409429.

Kahu, E., Nelson, K., \& Picton, C. (2017). Student interest as a key driver of engagement for first year students. Student Success, 8(2), 55-66. Available at: https://doi.org/10.5204/ssj.v8i2.379.

Kemp, N., \& Grieve, R. (2014). Face-to-face or face-to-screen? Undergraduates' opinions and test performance in classroom vs. online learning. Frontiers in Psychology, 5, 1278. Available at: https://doi.org/10.3389/fpsyg.2014.01278.

Kezar, A., Holcombe, E., \& Maxey, D. (2016). Rethinking faculty models/roles: An emerging consensus about future directions for the professoriate. New York: TIAA Institute.

Mehrabian, A. (1971). Silent messages. Belmont, CA: Wadsworth Publishing Co.

Mueller, B., Mandernach, B. J., \& Sanderson, K. (2013). Adjunct versus full-time faculty: Comparison of student outcomes in the online classroom. Journal of Online Learning and Teaching, 9(3), 341-352.

Myers, S. A., Zhong, M., \& Guan, S. (1998). Instructor immediacy in the Chinese college classroom. Communication Studies, 49, 240253. Available at: https://doi.org/10.1080/10510979809368534.

International Journal of Educational Studie Vol. 1, No. 2, pp. 102-109 2018

DOI: 10.53935/2641-533x.v1i2.78

Corresponding Author: Mingzhen Bao Funding: This study received no specific financial support.

Article History:

Received: 18 April 2018

Revised: 20 September 2018

Accepted. 13 November 2018

Accepted: 13 November 2018

Published: 21 December 2018

Publishing Group

| 108

National Center for Education Statistics. (2016). Digest of education statistics $2014 . \quad$ Retrieved from: http://nces.ed.gov/pubs2016/2016006.pdf.

Olwell, R. (2017). Moving beyond 2 percent. Inside Higher Education. Retrieved from: https://www.insidehighered.com/advice/2017/01/24/why-mentoring-students-so-low-faculty-agenda-and-what-can-be-doneabout-it-essay.

Rovai, A. P., Wighting, M. J., \& Liu, J. (2005). School climate: Sense of classroom and school communities in online and on-campus higher education courses. Quarterly Review of Distance Education, 6(4), 361-374.

Schutt, M., Allen, S., \& Laumakis, M. (2009). The effects of instructor immediacy behaviors in online learning environments. The Quarterly Review of Distance Education, 10(2), 249-252.

Trowler, V., \& Trowler, P. (2010). Student engagement evidence summary. York: Higher Education Academy. 


\section{Appendix End-of-course Survey Questions}

1. The instructor promotes active classroom participation of students.

2. The instructor fosters critical thinking throughout the course.

3. The instructor adds her/his perspective, such as knowledge and experience, to the course content.

4. The instructor communicates and promotes high expectations.

5. The instructor's feedback aligns with her/his communicated expectations.

6. The instructor provides feedback in a timely manner.

7. The instructor provides useful feedback for improving students' quality of work.

8. The instructor provides consistent grading across assignments.

9. I would recommend this instructor to another student.

10. Course assignments require me to think critically.

11. Hard work is required to earn a good grade in this course.

12. The course content (assignments/readings/study materials) is engaging.

13. Instructions for completing assignments are clear.

14. Clear instruction was given on how assignments would be graded.

15. The quality of my educational experience has met my expectations.

16. I would recommend this course to another student. 